\title{
Maths Sparks: Developing Community and Widening Participation
}

Aoibhinn Ní Shúilleabháin, School of Mathematical Sciences, University College Dublin, Dublin, Ireland. Email: aoibhinn.nishuilleabhain@ucd.ie

Anthony Cronin, School of Mathematical Sciences, University College Dublin, Dublin, Ireland. Email: anthony.cronin@ucd.ie

\begin{abstract}
Improving the engagement of university students in wider issues of teaching and learning is now an important driver in higher education. Additionally, widening the participation of those who access higher education is a matter of increasing prominence. In this paper we report on a case study initiative addressing both of these issues in a university mathematics department. Staff and university students collaborated in developing a series of mathematics workshops, called Maths Sparks, for secondary school pupils from disadvantaged socio-economic backgrounds. We report on the development of student-staff community as a result of establishing this programme and discuss the increased engagement and motivation of both university students and secondary pupils participating in the series of activity-based workshops.
\end{abstract}

Keywords: student engagement; student-staff community; widening participation; outreach

\section{Introduction}

Two prominent concerns of mathematics education in higher education are improving the engagement of undergraduate students who have chosen to study mathematics, and diversifying the range of students choosing to enter higher education to study mathematics. A lot of work has been done in the UK Mathematics, Statistics and Operational Research (MSOR) community in the past 15 years to widen participation to higher education of students with low socio-economic status (SES) (Cox and Bidgood, 2002). However, for these students there is a trend to move away from studying mathematics due to a lack of confidence in their ability to succeed in the subject and to a narrow understanding of mathematics (Lubienski, 2000). Participation in educational activities external to the classroom has been shown to influence students' attitudes about, and interest in mathematics, particularly for students from more disadvantaged social groups (Bhattacharyya et al., 2011). However, while many outreach activities can be aimed at gifted students, evidence from higher education institutes across the UK has shown that widening participation in such programmes is necessary to connect with more students of a diverse range of social backgrounds (Cox and Bidgood, 2002).

The Irish Higher Education Authority (HEA) has set a target for universities to widen participation rates for students from disadvantaged groups to $21 \%$ by 2016 (Higher Education Authority, 2014). Within University College Dublin (UCD), the 2015-2020 Strategic Report outlines a key objective to "attract and retain an excellent and diverse cohort of students, faculty and staff" (University College Dublin, 2014, p.10) and is focusing activities on widening participation to undergraduate programmes At UCD, the Access Centre has developed links with local schools, which have been designated by the Irish government as being disadvantaged, to provide opportunities for students to experience third leveli education via summer schools and other outreach events. There remain, however, distinct differences in the proportion of students from lower SES schools (described as DEIS - Delivering Equality of Opportunity in Schools) choosing to go to third level and, specifically, choosing to study mathematics (Higher Education Authority, 2014; Smyth et al., 2015). 
While it is important to focus on diversifying the range of students choosing to study mathematics at third level, it is also important to retain those students who are already studying mathematics at undergraduate level. Research has shown that engaging undergraduate students in activities involving both their peers and educators has a positive effect on student attainment (Duah and Croft, 2011) and many higher education institutions are already working to foster more studentstaff partnerships (Duah et al., 2014; University College Dublin, 2014). One of the key findings of the recent UK HEA report 'Building student engagement and belonging in Higher Education at a time of change' (Thomas, 2012) states that relationships between staff, students, and peers promote and enable student engagement and success in higher education. In addition, the report suggests that these relationships should be nurtured pre-entry to higher education. These findings relate both to current and potential university students; emphasising the importance of a sense of community within a mathematics department where students are encouraged to engage with their peers and with staff in various ways, from participating in outreach activities, to improving learning experiences (Duah and Croft, 2011; Trowler and Trowler, 2011).

With these factors in mind the authors set about developing a mathematics outreach programme where upper secondary students could engage with extra-curricular mathematics topics while learning from third-level peers in an active and collaborative environment. Inspired by the successful 'Maths Arcade' (Bradshaw, 2011) and 'Maths Circles' (Ó Conaill, 2012) initiatives, we set about establishing mathematics workshops which could be delivered to secondary school students (henceforth referred to as 'pupils') by their undergraduate colleagues. These workshops would incorporate mathematical games, problems, and puzzles which would involve mathematical topics outside of the post-primary curriculum. With this programme we hoped to foster an appreciation of, and interest in, mathematics for the secondary pupils which could, in time, lead them to consider choosing a mathematical programme at third level. Simultaneously, we hoped this programme would begin to develop a learning community of staff and students within the School of Mathematical Sciences at UCD.

In the following two sections we report on the outcomes of this pilot case study.

\section{Establishing Maths Sparks}

In December 2014, students in the School of Mathematical Sciences were invited to volunteer to participate in the inaugural Maths Sparks programme. Eleven students (eight undergraduate and three post-graduateii) volunteered to participate, and this group of students met with the authors in January 2015 to discuss potential mathematical topics to explore and incorporate over four workshops. These students grouped themselves into teams of 2-4 to develop content for their topic and over a number of weeks these workshops were planned, trialled, peer-reviewed, and refined prior to their final presentation.

It was important that pupils taking part in the workshops could appreciate the value of not being able to immediately solve a mathematical problem in their puzzles and games. Instead, activities within the workshops could provide a useful context to develop pupils' mathematical thinking where they did not always expect to win but could analyse the strategy behind a game (similar to the activities in Maths Arcade (Bradshaw, 2011)). Our university volunteers were therefore encouraged to develop activities which contrasted with traditional text-book exercises (O'Keefe \& O'Donoghue, 2011) and encouraged pupils to communicate their mathematical thinking to one another in 'making sense' of the problem/game/puzzle (Thomas et al., 2013). In the trialling of workshops it was also emphasised that the content:

- Explained some mathematical principle;

- Was solvable for the students;

- Could include a 'eureka' moment; 
- Was entertaining for students (Badger et al., 2012).

Teams also had the option of inviting a guest speaker (usually academic staff) to conclude their workshop and outline the applications of that particular topic to pupils. A list of developed workshop content is included in the Appendixiii.

Collaborating with the UCD Access Centre, pupils from six secondary DEIS schools local to the university were invited to participate in the workshop series. 42 pupils (in the final three years of upper secondary education) participated in the weekly two-hour workshops held over four weeks in an Active Learning Environmentiv room in the College of Science. These workshops were held on a Wednesday evening from $5 \mathrm{pm}-7 \mathrm{pm}$ and pupil transport was organised and sponsored by the UCD Access Centre. Workshop resources were purchased following successful application to the UCD Teaching and Learning 'SPARC' initiative.

\section{Generating Feedback}

In attempting to measure pupils' engagement in workshops, each of them was invited to participate in a post-workshop survey every week. The survey contained both quantitative and qualitative feedback, with some questions measured by Likert scale and other questions asking pupils to elaborate on their responses to the workshop. Observation field notes were recorded by the authors to note both the university students' and secondary pupils' participation as facilitators and attendees respectively. In addition, a focus group was held with the university students following completion of the workshop series in order to explore their responses to, and reflections of, their own learning from participation in the programme.

Qualitative survey responses were thematically analysed using open coding (Braun \& Clarke, 2006) and the findings from these responses, combined with our other data sources, are reported on below. While this case study was held as a pilot to identify the sustainability and suitability of such a programme, these initial findings provide a strong basis to continue with Maths Sparks in the next academic year as a means of widening university participation and developing studentstaff community within the department. We report below on feedback from students and pupils under three themes: pupil motivation and engagement, communication and transferable skills, and student-staff community. In our conclusion we suggest ideas for developing both the programme and subsequent research on this initiative.

\section{Findings and Discussion}

\subsection{Pupil Motivation and Engagement}

Through their participation in the Maths Sparks programme we wanted pupils to foster an appreciation of, and interest in, mathematics that might encourage them to continue their study of the subject. Despite having self-selected to participate in these workshops, 17 of the 35 pupils who completed the first survey were 'neutral' about or 'did not enjoy' mathematics in school (see Figure 1). 


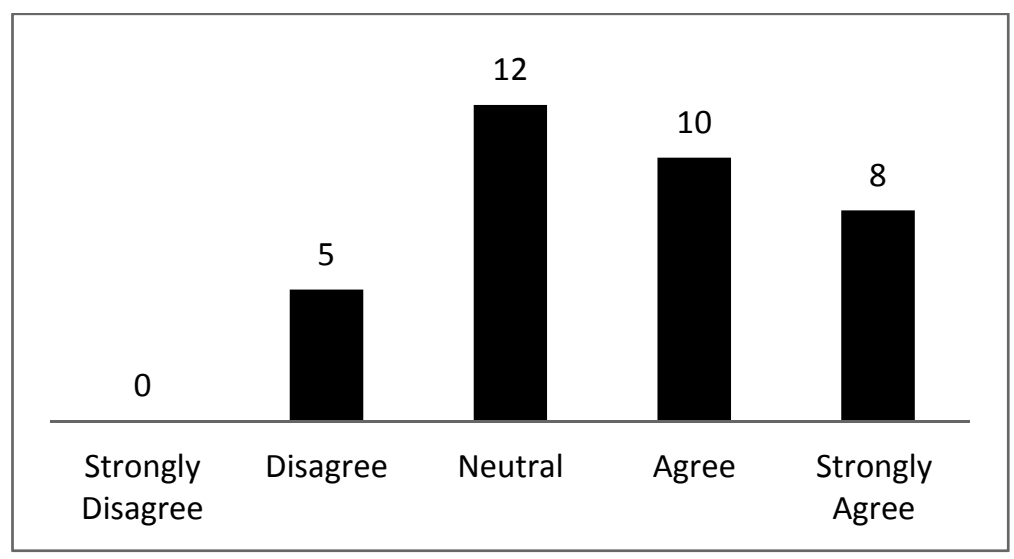

Figure 1. Pupil response to 'I usually enjoy maths in school', in week 1 post-workshop survey

This was surprising as we had expected that all pupils who volunteered to attend a four-week course explicitly focused on extra-curricular mathematics would have enjoyed the subject. Interestingly, all students reported on their positive engagement with the mathematical content contained within the first workshop and this favourable feedback continued throughout the rest of the four workshops.

Students continually noted that they enjoyed the mathematical content of the workshops since it was applicable to real life. They were encouraged to think about mathematics in a new way since the practical applications of concepts were emphasised in the workshops and in the concluding academic presentations. The positive responses from the students included the following:

"I liked the way maths I did here related to everyday life."

"It made me think about maths in a new way."

"Made me realise that maths can be used everywhere."

It was also a dominant theme within pupils' feedback that they enjoyed participating in these workshops since it contrasted with how they learned mathematics in school. Students continually referred to their experiences of learning mathematics as "boring", despite an emphasis in the new secondary curriculum on problem solving and constructivist approaches to teaching and learning (Cronin and Carroll, 2013; Ni Shuilleabhain, 2014). Students highlighted the fact that in the Maths Sparks workshops they liked "figuring out" the mathematics as a collaborative, social activity in the workshops.

It is worth noting that pupils found the mathematical content of the workshops challenging, but that this was, in the majority, viewed as positive.

"It was difficult and I like a challenge."

"I liked the challenge and learning the maths behind card tricks." 


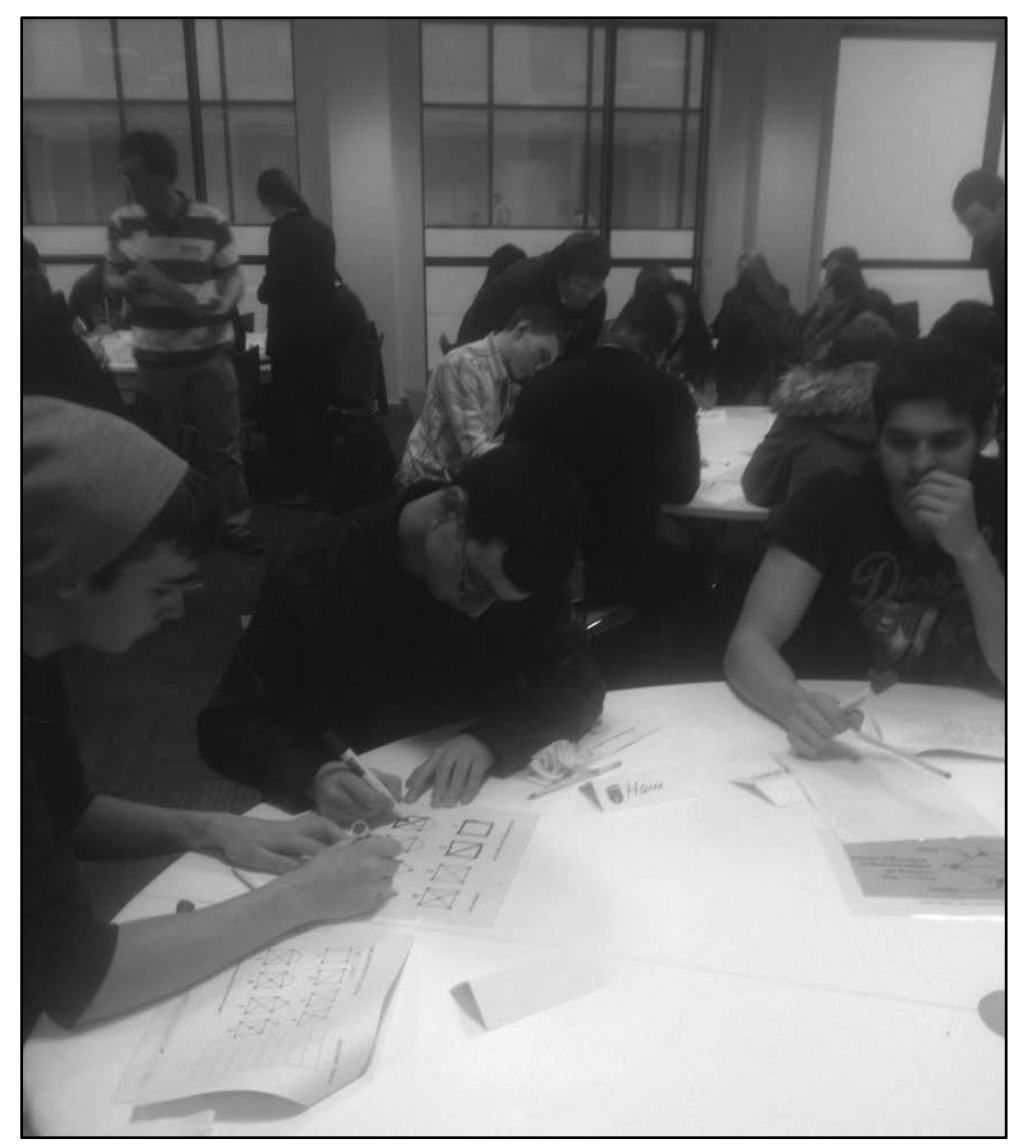

Figure 2. Pupils from different schools work together on a Graph Theory activity

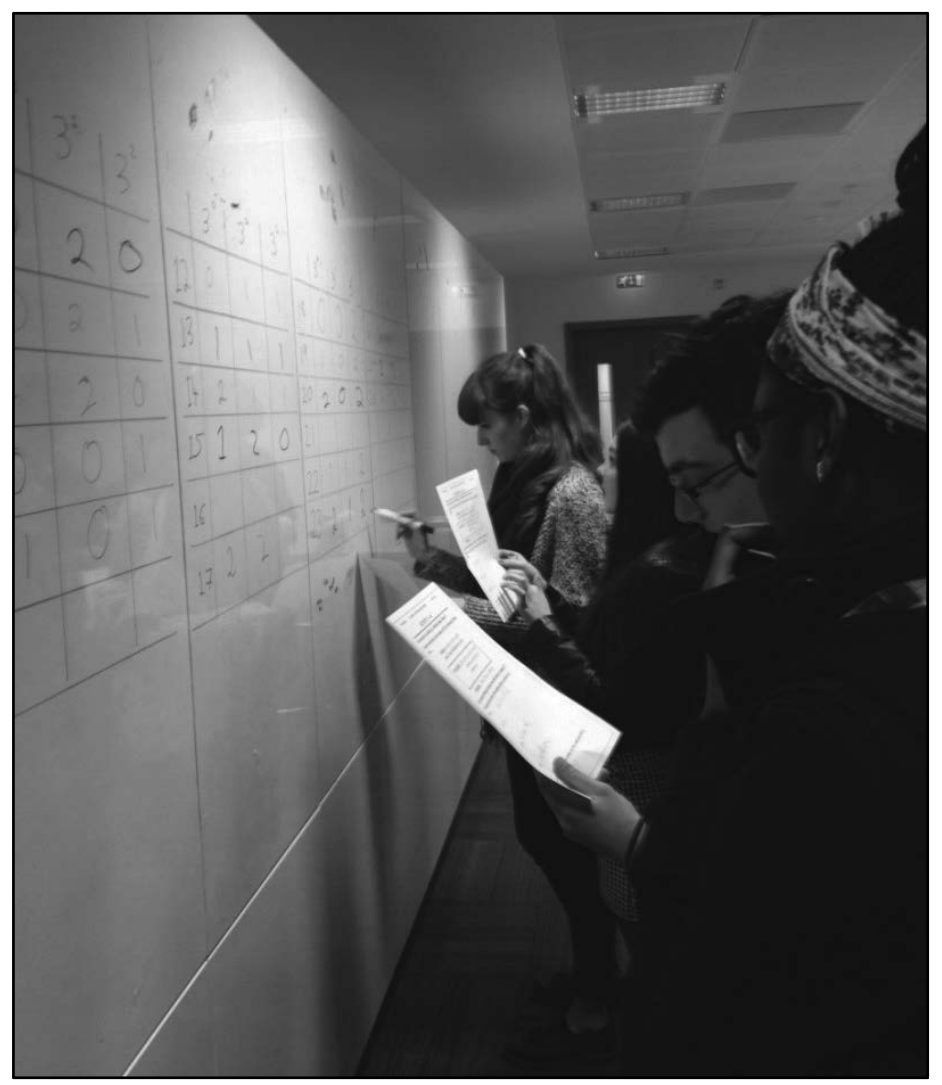

Figure 3. Pupils collaborate on calculations in base 3 
Pupils who had previously announced they were "no good" at mathematics began to develop their confidence in suggesting solutions as part of group and whole-class discussions and concluded that, while they might not be good at mathematics in school, they were good at this type of "university mathematics". There were a small number of negative reflections where pupils noted times when they would prefer to have been given the answer without having to conjecture and trial their ideas, but the majority of them responded positively to engaging with new mathematical topics and to having their university peers as workshop facilitators.

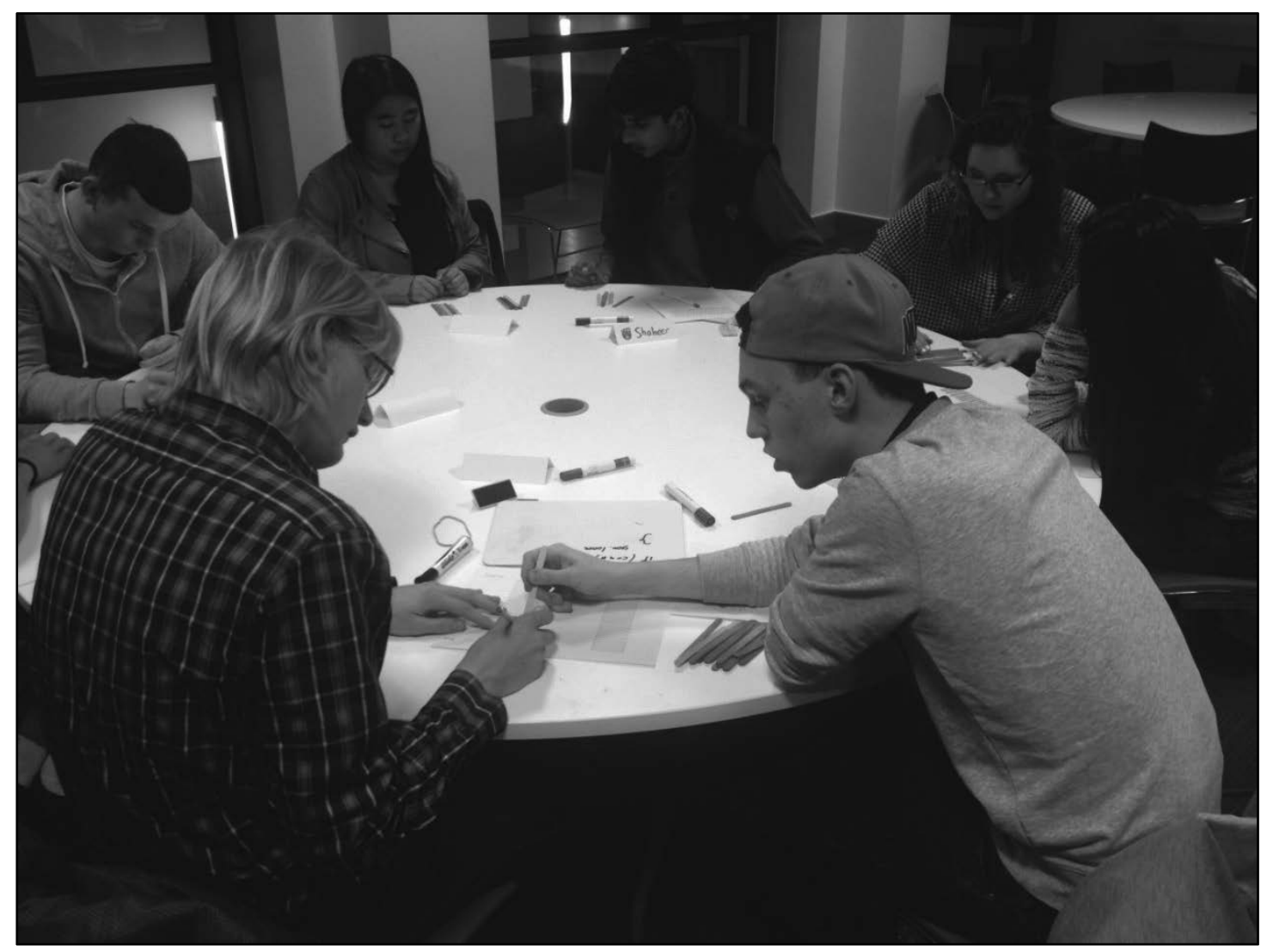

Figure 4. Pupils working out a strategy by backwards induction in the 'Stick/Nim Game'

In motivating these pupils to continue studying mathematics, one university student relayed a particular conversation she had had with the secondary school attendees. Following the first workshop pupils had joked about their future at the university as cleaners, but after the final workshop this same group of pupils spoke legitimately to one another about returning as undergraduate students. While this feedback was anecdotal within the focus group, we wish to pursue this line of research in widening student participation in the study of mathematics at third level. Within the workshop themselves, a small number of pupils expressed a new interest in continuing to study mathematics and other science subjects after secondary school. As yet, the conversion rate of these pupils cannot be tracked as they have not completed their secondary education, but we hope to incorporate this data as part of future studies.

\subsection{Communication and Transferable Skills}

Pupils found their university counterparts "friendly and helpful" and from classroom observations, the easy-going and sociable atmosphere in the room was notable. Pupils had fun deconstructing particular activities with university students and enjoyed collaborating on difficult problems. 


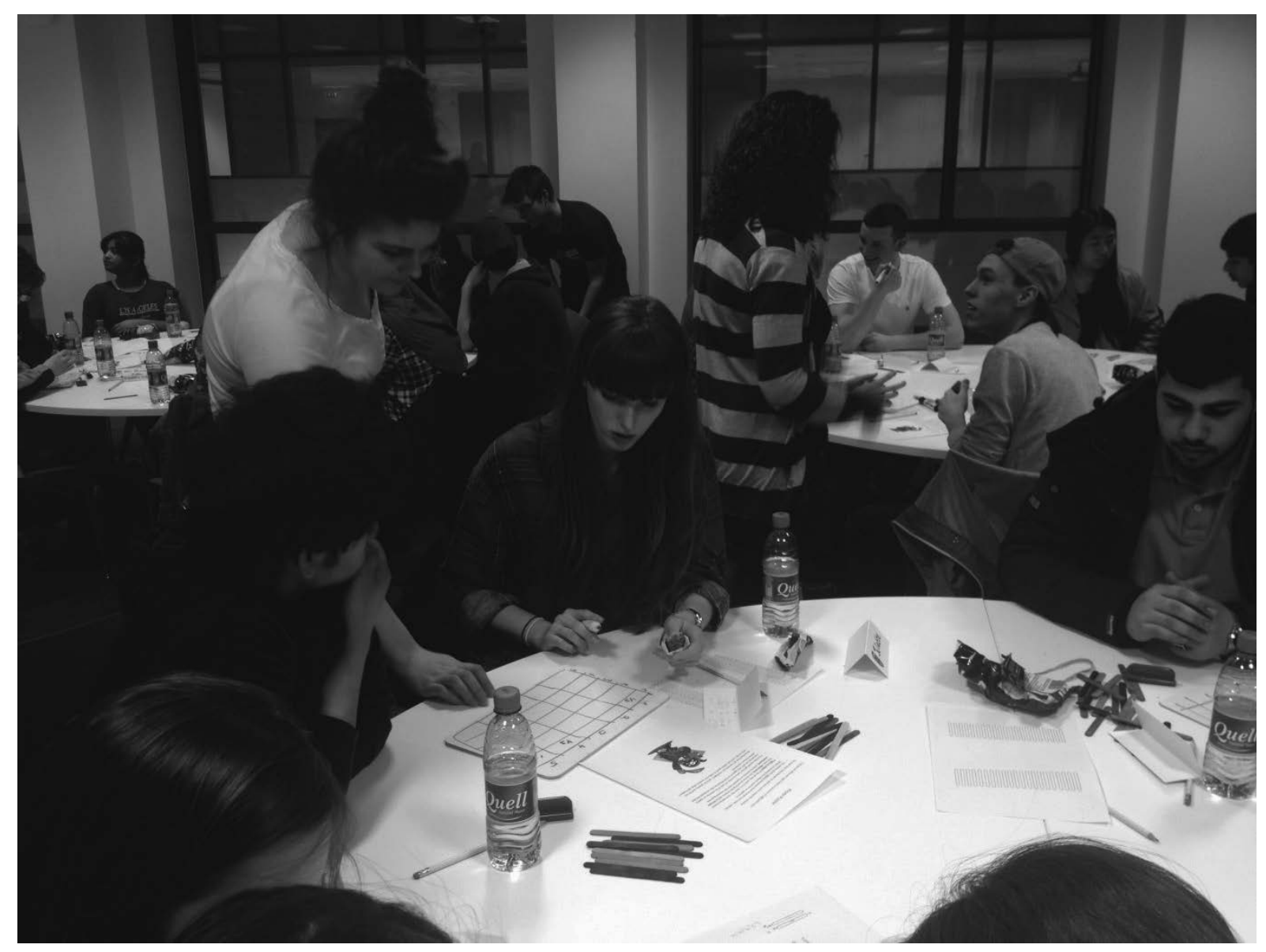

Figure 5. Pupils and students work together in attempting to solve the Pirate Puzzle

Over the four-week programme there was a marked improvement in our university students' communication and presentation skills from the first week where, "the [university] students seemed very nervous and it was hard to understand them - they talked a bit low", to them confidently conducting and directing full workshops in weeks three and four.

In the focus group, university students reported an increase in their confidence to present their mathematical knowledge - an important skill highlighted by the HE Mathematics Curriculum Summit (Rowlett, 2011). They also noted that this perceived improvement in their transferable skills would benefit them in giving presentations and in interviews with possible future employers.

\subsection{Student-Staff Community}

Due to their active participation in this programme, our university students began to see themselves as part of a community within the department. They built relationships with their peers across different year groups and with staff members through collaboratively developing workshop content, inviting guest lecturer speakers, and trialling workshops within the department. This is not an irrelevant finding since such increased student engagement within teaching and learning has been highlighted as a priority by the UK HEA and as a characteristic of mathematics departments with high levels of student satisfaction (Duah and Croft, 2011).

Reflecting on the workshops one university student noted: 
"I did not anticipate the relationship made between the students and the workshops and [I] was taken back by the attendance and involvement in all activities."

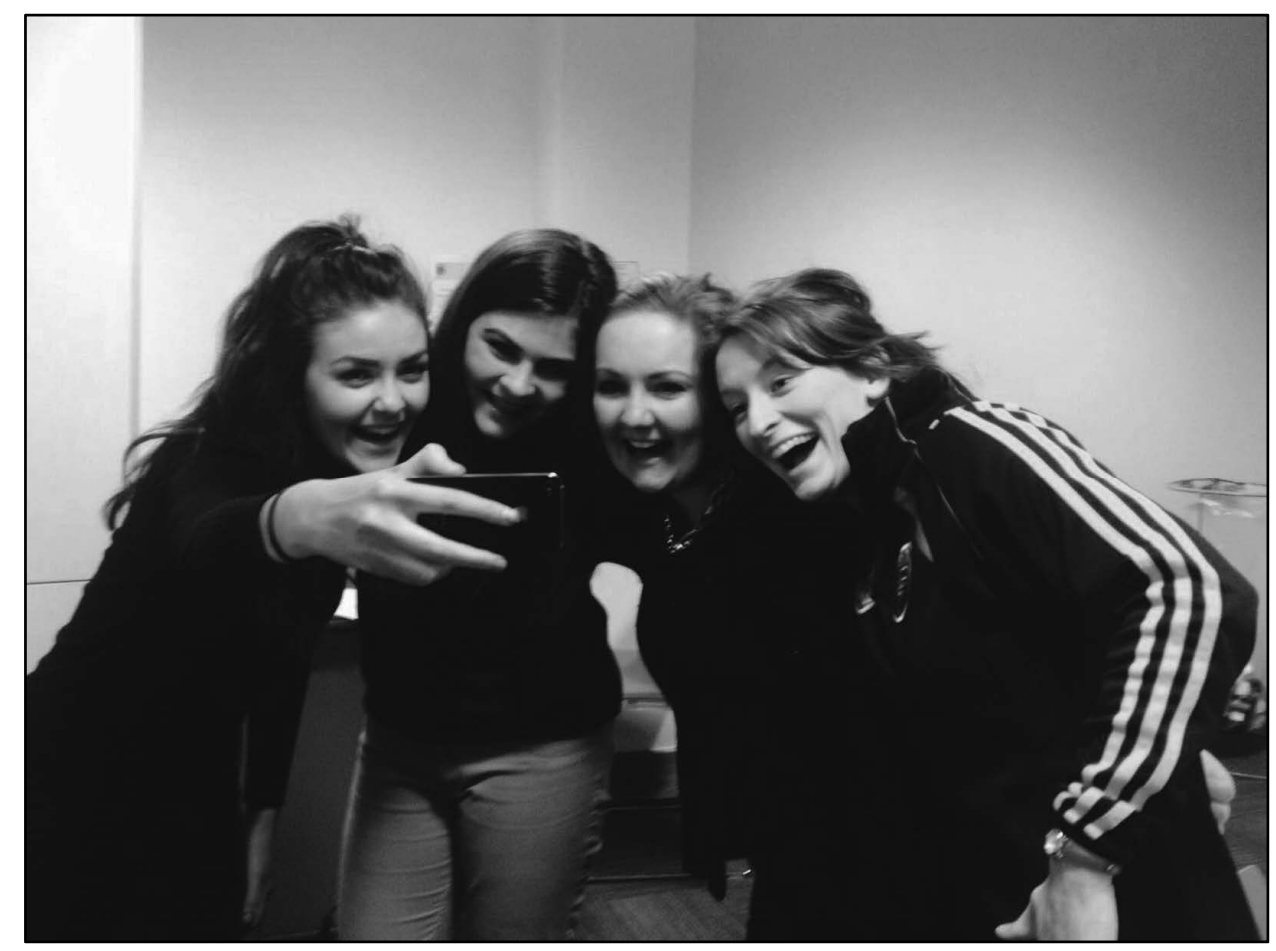

Figure 6. Group of undergraduate and postgraduate students who facilitated workshop 1

Students further noted that they liked the fact that they now knew peers at different levels of study within the department and were happy to advise and assist one another in deciding to study future mathematics modules. Students also suggested that more staff be involved in future to broaden the sense of community in the Maths Sparks group.

Each of the volunteers expressed a wish to return next year despite the lack of reward or credit for their work over 12 weeks of preparation and delivery ${ }^{\mathrm{v}}$ and a number of students have since been involved in additional outreach activities within the department ${ }^{\mathrm{vi}}$.

\section{Conclusion}

While the formations of peer networks and links with academic members of staff have been noted in the literature as playing a crucial role for student engagement and retainment (Bradshaw, 2011; Duah and Croft, 2011) the formal mentoring of pupils by university students is something we have not found explicitly reported. The Maths Sparks programme was a novel way of incorporating mathematics games and activities within a university department, with university students presenting and developing content for their second school peers under the guidance of their lecturers.

While developing the initial Maths Sparks programme took an investment of time on behalf of the authors, we found it of benefit in developing a student-staff community within our university department. While we cannot yet be certain of the conversion of secondary students in their continued study of higher mathematics at second or third level, we feel this was a valuable programme in developing pupils' opinion of and future plans to engage with mathematics. We hope to continue to develop this programme next year with scope to further investigate the development of community as a result of student-staff participation and the enhancement of students' transferable skills as a result of participating in these outreach workshops. We would also like to 
investigate the possible impact of increasing pupils' likelihood of pursuing mathematics at third level.

While many higher level institutions offer pastoral support to visiting pupils, we feel this academic support across learner-levels can be positively exploited and we hope to continue developing this idea.

\section{Acknowledgements}

This project was funded by UCD SPARC, a UCD Teaching and Learning initiative to facilitate the delivery of student-staff partnerships, and was supported by the UCD Access Centre.

The authors would like to thank Noel-Anne Bradshaw for her generous communications explaining both the rationale and practicalities of the Maths Arcade and the staff of the UCD Access Centre, particularly Anne Lavelle, for their enormous support in setting up the initial Maths Sparks programme.

\section{Appendix}

\subsection{Pupil Survey Week 1}

Please rate the following on the scale provided:

\begin{tabular}{|l|l|l|l|l|l|}
\hline I usually enjoy maths in school. & $\begin{array}{c}\text { Strongly } \\
\text { Agree }\end{array}$ & Agree & Neutral & Disagree & $\begin{array}{c}\text { Strongly } \\
\text { Disagree }\end{array}$ \\
\hline $\begin{array}{l}\text { I enjoyed participating in this } \\
\text { workshop. }\end{array}$ & & & & & \\
\hline $\begin{array}{l}\text { I feel like I learned something } \\
\text { from participating in this } \\
\text { workshop. }\end{array}$ & & & & & \\
\hline $\begin{array}{l}\text { It was difficult working on } \\
\text { problems that are very different } \\
\text { to my school textbook. }\end{array}$ & & & & & \\
\hline $\begin{array}{l}\text { I enjoyed working with other } \\
\text { students that I did not know. }\end{array}$ & & & & & \\
\hline
\end{tabular}

What did you like about the workshop?

What did you dislike about the workshop?

What could we do better in the next workshop? 


\begin{tabular}{|c|c|c|}
\hline \multicolumn{3}{|c|}{ Maths Sparks Programme 2015 } \\
\hline Week & Part 1 & Part 2 \\
\hline 1 & $\begin{array}{c}\text { Cryptography (Caesar } \\
\text { Cipher \& Vigenère Cipher) }\end{array}$ & $\begin{array}{c}\text { Cryptography \& Presentation } \\
\text { 'Coding \& Encryption' }\end{array}$ \\
\hline 2 & $\begin{array}{c}\text { Graph Theory (Eulerian \& } \\
\text { Hamiltionian Paths) }\end{array}$ & $\begin{array}{c}\text { The Mathematics of Angry } \\
\text { Birds }\end{array}$ \\
\hline 3 & $\begin{array}{c}\text { Modulo Arithmetic/Number } \\
\text { Theory (27 Card Trick) }\end{array}$ & $\begin{array}{c}\text { Probability (Liar's Dice) \& } \\
\text { Presentation 'Mathematics of } \\
\text { Card Tricks' }\end{array}$ \\
\hline 4 & $\begin{array}{c}\text { Game Theory (Stick/Nim } \\
\text { Game) }\end{array}$ & $\begin{array}{c}\text { Game Theory (Prisoner's } \\
\text { Dilemma) \& Presentation } \\
\text { 'Financial Maths and Game } \\
\text { Theory' }\end{array}$ \\
& & $\begin{array}{c}\text { Thery } \\
\end{array}$ \\
\hline
\end{tabular}

\section{References}

Badger, M., Sangwin, C., Ventura-Medina, E. and Thomas, C. (2012). A Guide to Puzzle-Based Learning in STEM Subjects. University of Birmingham: National HE STEM Programme.

Bhattacharyya, S., Nathaniel, R. and Mead, T. P. (2011). The Influence of Science Summer Camp on African-American High School Students' Career Choices. School Science \& Mathematics, 111(7), pp. 345-353.

Bradshaw, N. (2011). The University of Greenwich Maths Arcade. MSOR Connections, 11, pp. 2629.

Braun, V. and Clark, V. (2006). Using thematic analysis in psychology. Qualitative Research in Psychology, 3, pp. 77-101.

Cox, B. and Bidgood, P. (2002). Widening Participation in MSOR. MSOR Connections, 2(1), pp. 15-19.

Cronin, A. and Carroll, P. (2013). Building Analytic Skills in Undergraduate Busineess Students: The Impact of Project Maths. Paper presented at the Fifth Conference on Research in Mathematics Education MEI 5, St. Patrick's College, Drumcondra, Dublin 9.

Duah, F. and Croft, T. (2011). The first MSOR Student Engagement Event. MSOR Connections, 11(2), pp. 17-20.

Duah, F., Croft, T. and Inglis, M. (2014). Can peer assisted learning be effective in undergraduate mathematics. International Journal of Mathematics Education in Science and Technology, 45(4), pp. 552-565.

Rowlett, P., ed. (2011). HE Mathematics Curriculum Summit. Birmingham, U.K.: Maths, Stats and OR Network. Available via: www.mathcentre.ac.uk/resources/uploaded/summitreport.pdf 
Higher Education Authority. (2014). Consultation Paper: Towards the development of a new National Plan for Equity of Access to Higher Education. Dublin: Higher Education Authority.

Lubienski, S. (2000). Problem Solving as a Means Toward Mathematics for All: An Exploratory Look Through a Class Lens. Journal for Research in Mathematics Education, 31(4), pp. 454-482.

Ni Shuilleabhain, A. (2014). Lesson study and Project Maths: A Professional Development Intervention for Mathematics Teachers Engaging in a New Curriculum. In S. Pope (Ed.), 8th British Congress of Mathematics Education (pp. 255-262). Nottingham University.

Ó Conaill, C. (2012). Maths Circles Ireland: First Year Handbook (S. o. M. Sciences, Trans.). Cork, Ireland: University College Cork.

O'Keefe, L. and O'Donoghue, J. (2011). A Review of School Textbooks for Project Maths: National Centre for Excellence in Mathematics and Science Teaching and Learning.

Smyth, E., McCoy, S. and Kingston, G. (2015). Learning from the Evaluation of DEIS. Dublin: Economic and Social Research Institute.

Thomas, C., Badger, M., Ventura-Medina, E. and Sangwin, C. (2013). Puzzle-based Learning of Mathematics in Engineering. Engineering Education, 8(1), pp. 122-134.

Thomas, L. (2012). Building student engagement and belonging in Higher Education at a time of change: a summary of findings and recommendations from the What Works? Student Retention \& Success programme. UK: Higher Education Academy.

Trowler, V. and Trowler, P. (2011). Student Engagement Toolkit for Leaders. UK: Leadership Foundation for Higher Education.

University College Dublin. (2014). Ireland's Global Univeristy: Strategy 2015-2020. Dublin 4: University College Dublin.

\footnotetext{
'Third level education (also referred to as 'higher education') refers to post-secondary education.

ii Including two Professional Masters in Education students who will qualify as secondary mathematics teachers.

iii Please contact authors for further details of resources and workshops.

iv ALE Rooms contain multiple white boards and round tables (which can each seat nine students).

$\checkmark$ All eleven of the university students involved in Maths Sparks are currently being vetted by the university's Diploma Supplement group to have their contribution to this project added to their transcripts. vi At the time of going to press, five of the Maths Sparks university students have being involved with further outreach
activities including the UCD Summer School and the UCD Leaving Certificate Maths Support sessions.
} 